\title{
Intelligent System Application of Health Consultation based on Web and Android Apps "SIDIKA"
}

\author{
Nuril Anwar \\ Informatics Engineering Study \\ Program \\ Universitas Ahmad Dahlan, \\ Yogyakarta, Indonesia
}

\author{
Khoiriyah Isni \\ Public Health Study Program \\ Universitas Ahmad Dahlan, \\ Yogyakarta, Indonesia
}

\author{
Lovandri Dwanda Putra \\ Primary School Teacher \\ Education Study Program \\ Universitas Ahmad Dahlan, \\ Yogyakarta, Indonesia
}

\begin{abstract}
Public Health is essentially a science that consists of various disciplines. Health promotion is one of the sciences with the output in the form of products for the community, especially in the health sector, which aims to monitor programs in the Community Health Centers. Youth Care Health Services, while providing adolescent health information and counseling services. Optimization of Adolescent Health Care Services and counseling programs is needed as the development of information technology resolves the problem of lack of information in the community, a web-based information system is created that can help doctors or health experts in providing knowledge and health information about adolescents, as well as conducting direct discussions with adolescent through counseling features. SIDIKA is a health information system based on web and android technology dedicated specifically to adolescent who need health information about adolescent. This system provides counseling features that can connect adolescent with doctors or health care professionals directly. With the existence of the SIDIKA system, it is expected to be able to provide solutions in terms of the ease of program implementation of Adolescent Health Care Services and counseling between adolescents with doctors or health experts. In addition, making adolescent feel comfortable in consultation without any shame.
\end{abstract}

\section{Keywords}

Public Health, SIDIKA Application, Adolescent Health Care Services \& Community Health Centers

\section{INTRODUCTION}

Public Health is essentially a science consisting of various disciplines such as biology, physics, chemistry, medicine, environment, sociology, psychology, anthropology, economics, administration, education and others. But in general, the disciplines that support the establishment of public health as a science or better known as the 8 pillars of public health, one of which is health promotion, where health promotion must be able to create products for the community, especially in the health sector, one of which monitors programs at the Community Health Center.

The Community Health Center is a functional organization that carries out comprehensive, integrated, equitable, acceptable and affordable health efforts by the community, with active community participation and using the results of the development of appropriate science and technology, with costs that can be borne by the government and the community.

The Community Health Center makes efforts to improve the quality of adolescents by providing Adolescent Health Care Services, while providing adolescent health information and counseling services. This program is devoted to adolescents because in addition to being the next generation and assets for the nation, adolescents are also human resources for national development in the future. So that the health problems of adolescents need to get special and serious attention to improve the quality of adolescents in achieving the continuity and success of national development goals.

Various parties feel that the Youth Care Health and counseling Service program has not run optimally because there are problems that are often complained of by adolescents who have difficulty in conducting consultations at the Community Health Centers because doctors or health experts on adolescent health do not always exist in each region. Community Health Centers service hours also coincide with adolescent school hours, then there are other obstacles that are internal factors from adolescents themselves, namely feeling ashamed to conduct consultations about adolescent health.

From these problems, the Community Health Center is deemed necessary to maximize the use of information technology to help overcome various problems in the implementation of the Adolescent Health Care program and counseling. The Community Health Centers wants a webbased information system that can help doctors or health experts in providing knowledge and health information about adolescents, as well as conducting direct discussions with adolescent through counseling features. Meanwhile, to connect adolescent with doctors or health experts, an Android-based application is needed that is more easily accessible from anywhere, anytime and anywhere as long as the smartphone has an internet connection. Because it cannot be denied that at this time smartphone is not a luxury item, almost all adolescent have it.

Therefore SIDIKA is made up of a web and android technology based health information system dedicated specifically to adolescent who need health information about adolescent. This system provides counseling features that can connect adolescent with doctors or health care professionals directly. With the existence of the SIDIKA system, it is expected to be able to provide solutions in terms of the ease of implementation of the Adolescent Health Care Services program and counseling between adolescents with doctors or health experts. In addition, making adolescent feel comfortable in consultation without any shame.

\section{STUDY OF LITERATURE}

One of the factors related to adolescent problems in Purworejo Regency (280 cases of pregnant adolescents, 53 cases of HIV/AIDS, and early marriage) is a lack of knowledge of adolescents about reproductive health. To overcome this, reproductive health education is needed by utilizing the media that many adolescent have, namely 
smartphones. Objective: To develop an android-based adolescent reproductive health education application at Pius Purworejo High School. Method : Research and development with ADDIE development model with needs analysis, concept design, and application development stage. Validation was carried out by material experts, media experts, and practitioners of high school reproductive health learning. Applications were assessed by 35 students of class XI of Pius High School. Results: Required features based on needs analysis include offline access, login, short material, quiz with options, answer keys , myth / facts, IMT Converter, music, and educational videos. Concept design is done by determining material and questions (26 quiz questions and 20 myth / fact questions), supporting features (player accounts, settings, about, tutorials), score concepts, and asset data (symbols, icons, .png). The application was made and then validated by the validator for revision of the application. Material experts correct typos and word changes in the material and questions. Media experts suggest that the correction is more attractive. There is no correction from the last validator. The percentage of application assessment by students is $85 \%$ (very good). Conclusion: In the opinion of Pius high school students, the application is interesting to use, easy to understand, and in accordance with the needs of high school adolescent. It is recommended to update the display, backsound, and more quiz questions. [1]

In the modern era, every individual is required to have the ability to access various kinds of information needed online. This happens through technological advances that gave birth to the existence of digital media. Health information is always needed because it becomes a primary need for the community. This is certainly can not be separated from the variety of health information media used by every community. More specifically in the modern world, there are numerous ease of access to information that can be found by urban community. The study indicates that: (1) The urban community seeks health-related information via television, health and medical websites and social media i.e. information sharing from Whatsapp Group, LINE Group, and BBM Group; (2) The perceived barriers to accessing information media are psychological barriers, i.e concerns over fake health news and linguistic barriers, i.e. the use of scientific language or medical terms that is difficult to understand.[2]

The absence of mobile-based health information systems that can integrate all hospitals, health centers, health clinics and pharmacies in Pekalongan, will bother people who need health information quickly, accurately, anytime and anywhere. like schedule doctor, inpatient room availability information for all health institutions, so with this information so people can make decisions quickly and accurately.this study intends to support a solution to the difficulty in obtaining accurate information, such as the schedule of doctors, inpatient, the stock of blood, hospital through the development of information systems that integrate health-care institutions in the city of Pekalongan.[3]

To develop a quality software "System development life cycle" is the best technique to be adopted. Software has the ability to map itself on a Quality Model so that its working can be seen on a set of factors along with their criterion. By this correlation better results can be gained from the working of software on every environment. To achieve a quality product it is necessary for the developer to understand how it can be achieved. Theoretical study is the main phase of understanding the performance of software. For achieving a quality product, in this paper the collaboration of SDLC with
Criteria of Quality models will be seen for the better working of a software system.[4]

Mobile technology has seen a steep rise in its demand and usage, which has further increased the need for specialized software for mobile devices. For developing mobile applications, existing software development process models are incorporated. But looking at the remarkable growth of mobile devices, the complexity involved in development of mobile applications needs a dedicated life cycle process model, instead of using traditional life cycle process models. Although many existing life cycle models are adapted for mobile apps development but there are certain constraints that needs to be addressed specifically, such as Performance Factor, Power Factor, Band Factor, Connectivity Factor, Context Factor, Graphic Interface Factor, Input Interface Factor. It is a stimulating task to develop mobile application due to these technical constraints. In this paper, a comparative analysis of traditional software life cycle models that are widely used in software development and also discussed the strengths and weakness of using these models for mobile application development. It also emphasize on need for dedicated mobile application development life cycle process in order to provide high quality mobile apps and minimize mobile app development problems and errors that are faced at later stage.[6]

\section{RESEARCH METHODS}

\subsection{Data collection}

Data collection using the method:

\section{A. Observation method}

Observation method is done by visiting the client directly to obtain data and documentation in the form of photos.

\section{B. Interview method}

Is a method that is carried out by direct interviews with clients. Data taken in the form of data system requirements.

\subsection{Software Development Methods}

\section{A. System Development Life Cycle (SDLC)}

System Development Life Cycle - It is a process of creating information systems, and the models and methodologies that people use to develop these systems. The SDLC process was designed to ensure that end-state solutions meet user requirements in support of business strategic goals and objectives. SDLC is used to develop, maintain and replace Information System. Systems are so big and complex that teams of architects, analysts, programmers, testers and users must work together to create the millions of lines of customwritten code that drive enterprises. SDLC is used to correct problems in existing system, and to improve the system quality and structure. It certainly eases the process of building a system and helps reduce failures such as unclear objectives, possibility of not meeting user needs, or cost overruns. The most important part in SDLC is communication. Without good communication it is not possible to satisfy the customer, and that may lead to errors and omissions which can be expensive in the end. The flow of the SDLC process can be seen as in Figure 1; 


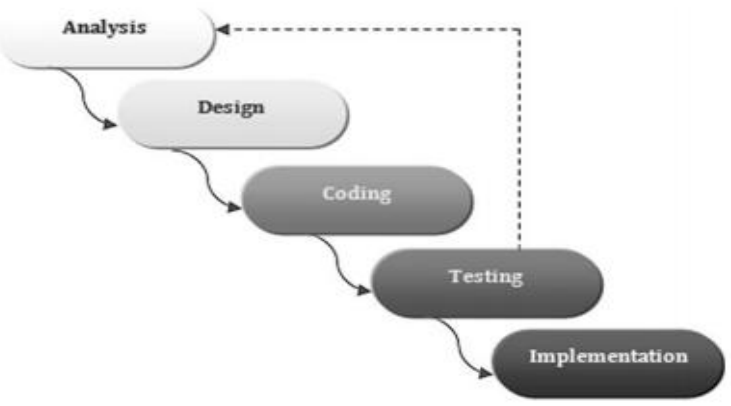

Fig. 1. SDLC Waterfall Model [5]

\section{B. Mobile Application Development Lifecycle (MADLC)}

Proposed a Mobile Application Development Lifecycle (MADLC) that includes the following phases: Identification, Design, Development, Prototyping, Testing and Maintenance.[7]

1) Identification Phase:-In the first phase, ideas are collected and categorized. The ideas can come from the customer or from the developers.

2) Design Phase:-In this phase, the idea from the mobile application team is developed into an initial design of the application.

3) Development Phase:-In this phase, the application is coded. Coding for different modules of the same prototype can proceed in parallel.

4) Prototyping Phase: -In this phase, the functional requirements of each prototype are analyzed; the prototypes are tested and sent to the client for feedback. After feedback, the required changes are implemented through the development phase. When the second prototype is ready, it is integrated with the first prototype, tested and then sent to the client. The development, prototyping and testing phases are repeated until the final prototype is ready.

5) Testing Phase:-The testing of the prototype types is performed on an emulator/simulator followed by testing on the real device.

6) Deployment Phase : - After the testing is completed and the final feedback is obtained from the client, the application is ready for the deployment.
7) Maintenance Phase: - Feedback is collected from users and required changes are made in the form of bug fixes or improvements. Figure 2 shows Mobile Application Development Lifecycle

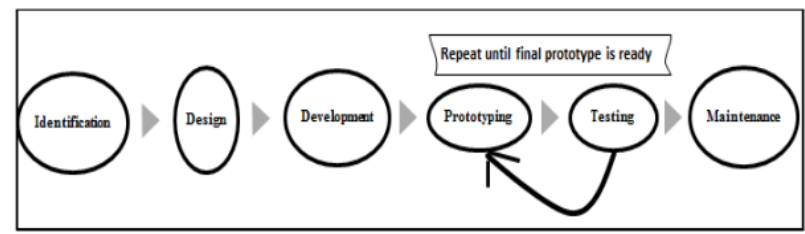

Fig. 2. Mobile Application Development Lifecycle (MADLC) [7]

The hardware and the relevant software required for running the system must be made fully operational before implementation. The conversion is also one of the most critical and expensive activities in the system development life cycle. The data from the old system needs to be converted to operate in the new format of the newly developed system. The database needs to be set-up with security and recovery procedures fully defined. Bugs must be rectified and requested changes completed

\section{RESULTS \& DISCUSSION}

\subsection{System Implementation}

\section{A. Android Based Application}

Home in Figure 3. describes the start page in the application that displays the application, information, and other important things.

\section{B. Question Answering System}

Question Answering System (QAS). Through QAS, users can enter questions with using natural language and computers can understand the question in question, then the application will provide the appropriate answer Question Answering System (QAS) is a system that allows a computer to understand the purpose of the questions posed by users by using natural language and respond to these questions based on available information [8]. QAS is grouped into two parts, namely QAS with open domains and QAS with closed domains. QAS with an open domain allows the system to answer 


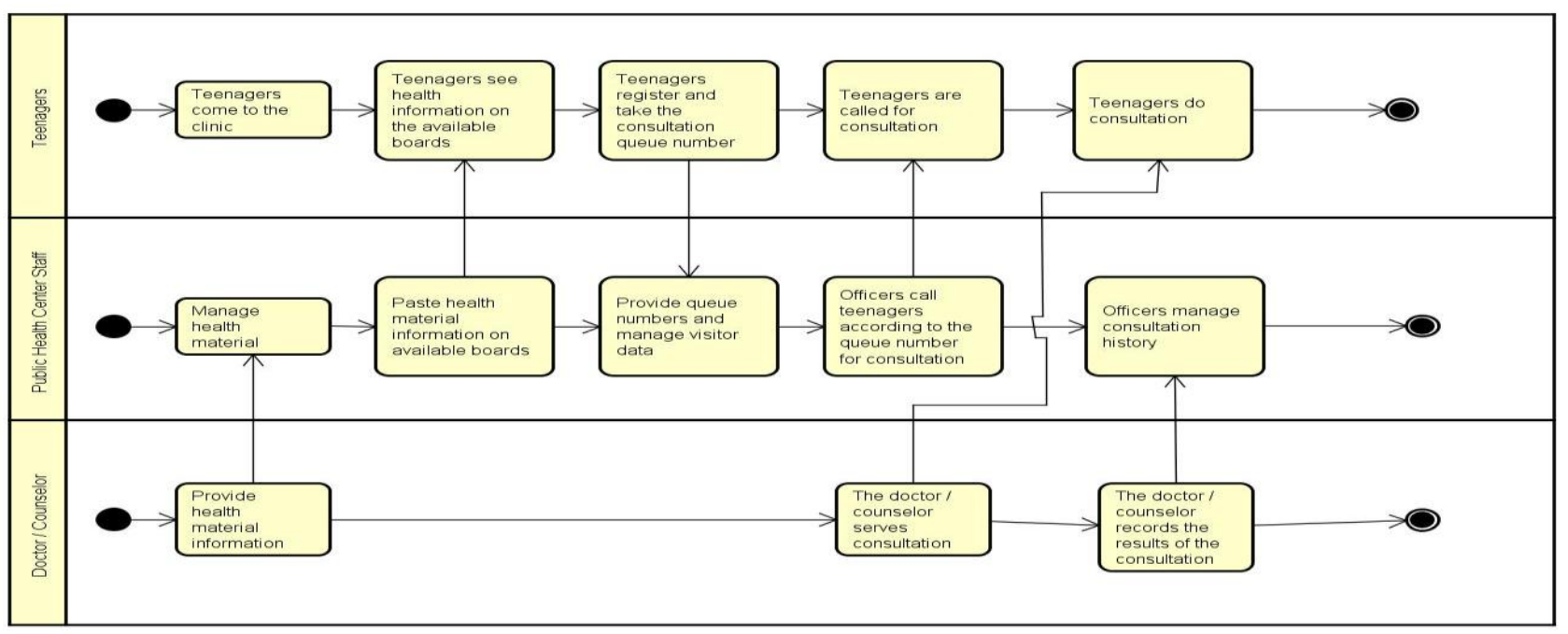

Fig. 3. Business Process Before There Is a System

Program Business Process at community health centers Before the System Is Available The flow of the business process of the PKPR service program at the health clinic before the system can be seen in Figure 3.

The program business process at the Health Center before the existence of the adolescent health consultation system was to disseminate information through conventional media such as posters, bulletin boards, and brochures so that the dissemination of information about adolescent health care programs could not be comprehensive and equitable, especially adolescent who wanted to consult.
The flow of the program business process after the adolescent health consultation system was created was initiated by opening the SIDIKA system. The system will display various adolescent health materials in the form of articles on the SIDIKA adolescent health consultation system. In addition to material, adolescent can also send messages to counselors in the form of personal questions. As for general questions, adolescents can ask the discussion forum according to the topic of discussion that they want to ask. With this system adolescent and counselors can easily connect to each other and save more time in consultation.

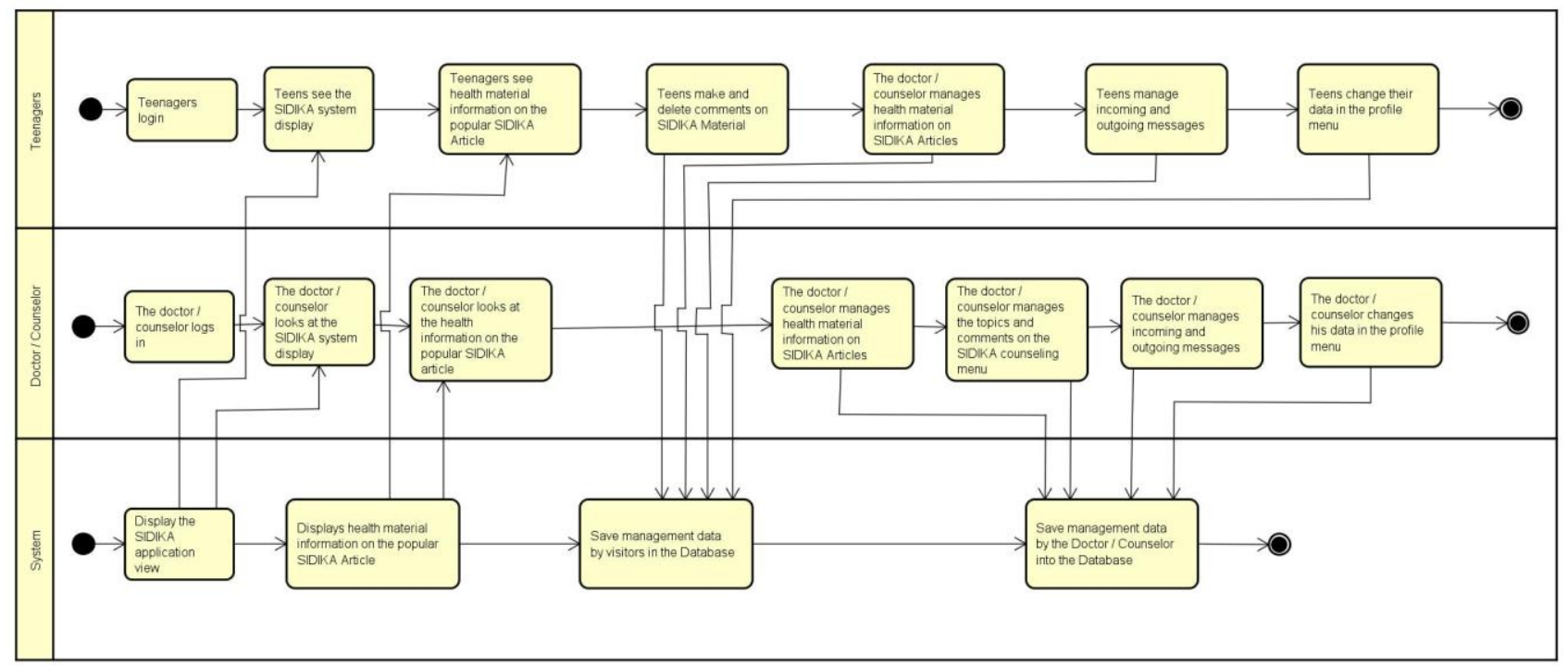

Fig. 4. Business Process After a system

General questions. Whereas QAS with closed domains can only answer questions with specific topics, for example about music, weather, and books. In order to understand the meaning of the question in QAS, the preprocessing stage is needed to extract text information. There are several methods used and can be combined as needed. In this study, preprocessing will be used in the tokenization method text questions, POS tagging, and Named Entity Recognition. Tokenization is a division process the text becomes a basic unit (token). In general tokens are separated by spaces and punctuation, so that each token is represented in word form or punctuation [9]. 

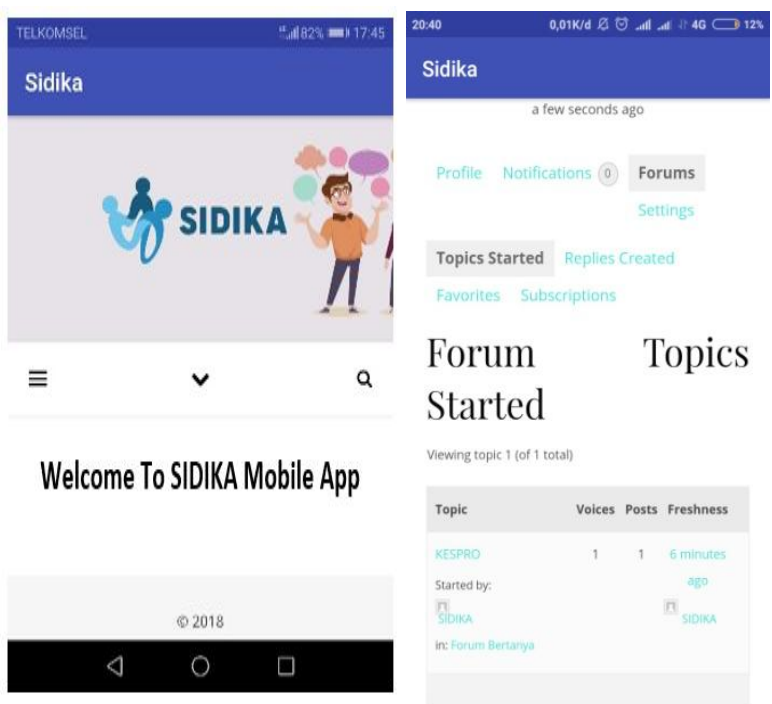

Forum

Topics Started

\section{Fig. 5. Display of the SIDIKA mobile application home page}

This home is useful to make the beginning of the user using the application like and trust that the application is trusted.

\section{Web Based Applications}

The home page in Figure 6. describes the initial page in the web base application containing the content that displays the application, information, and other important things.
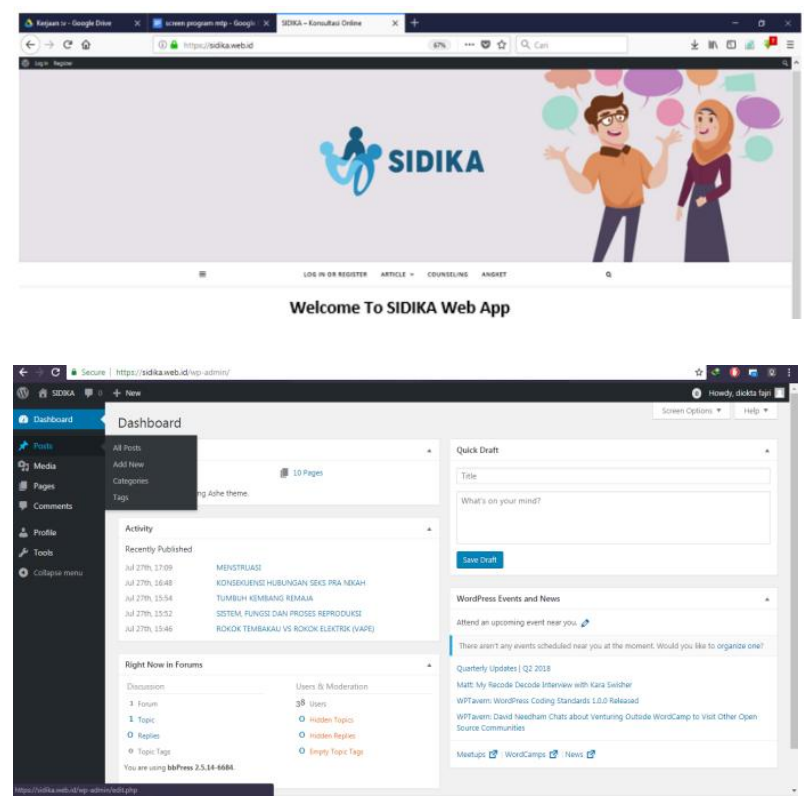

Fig. 6. Display of the SIDIKA web page.

This home is useful to make the beginning of the user using the application like and trust that the application is trusted www.sidika.web.id

\section{Testing a Software Product}

The developers are bound to made inadvertent errors while developing a software product. These errors are required to be uncovered and then adjusted before the product is delivered. Several questions deserve their due attention during this stage. For example, how the test should be conducted? Do researchers need to develop a formal plan for the exam? If the whole program as a whole has to be tested or tests carried out only on smaller parts? Do researchers need to repeat the test after each component has been added? Do researchers need to involve customers? [4]

\section{Testing Strategies}

\section{1) Unit Testing or Component Testing}

It refers to tests that verify the functionality of a specific section of code (in conventional design at the function level and in object oriented design at the class level). These type of tests use white-box style as those are developed by the developers during development phase to make sure that the code is working correctly. It is likely that the unit testing alone may not provide exhaustive results but it does assure that the building blocks satisfactorily in stand-alone position.

\section{2) Integration Testing}

When stand-alone components are integrated it is likely that they may repel each other or they lose data interface. It is good to test the integrated components as an entity. Integration testing does the job. That is Integration testing is any type of software testing that seeks to verify the interfaces between components against a software design. This requires the knowledge how components have been integrated? Incremental (bottom-up or top-down) or plunged? Regression testing and smoke testing are typical examples of integration testing.

\section{3) Testing Methods}

The systematic measurements of a product are the ways how it is tested to achieve the assurance of quality. Various methods have been introduced for the purpose. 
Table 1. System Testing SIDIKA

\begin{tabular}{|c|l|l|}
\hline $\begin{array}{c}\text { No } \\
\text { Fungsi }\end{array}$ & \multicolumn{1}{|c|}{ Fungsi } & \multicolumn{1}{c|}{ Task / Tugas } \\
\hline F1 & Login & Log in to enter the SIDIKA system by entering a username and password \\
\hline F2 & Article & The main page from SIDIKA \\
\hline F3 & AHCS & See information and material about adolescent health about Adolescent Health Care Services \\
\hline F4 & R/H & See information and material about adolescent health about Reproduction Health \\
\hline F5 & HIV & See information and material about adolescent health about HIV \\
\hline F6 & Drugs & See information and material about adolescent health about drugs \\
\hline F7 & Smoker & See information and material about adolescent health about the dangers of smoking \\
\hline F8 & Adolescent & See information and material about adolescent health about adolescents \\
\hline F9 & Counseling & Create new topics and give questions to counselors through discussion forums \\
\hline F10 & My Account & Complete Profile and display notifications \\
\hline F11 & Logout & Log out to exit the SIDIKA system \\
\hline
\end{tabular}

\section{CONCLUSION}

Conclusions that can be drawn from the research design of websites and android applications with the name "SIDIKA" namely; The creation of a web-based application is useful for doctors or health experts as a means of information that can help the process of publishing and delivering information, especially through internet media, so that it can accelerate the process of delivering information to adolescents. The creation of android-based apps can help facilitate adolescent in conducting consultations about adolescent health directly with doctors or health experts.

\section{ACKNOWLEDGMENTS}

Thanks to the experts to the higher education research ministries who have funded this research from the beginning to the end, the Institute of Research and Community Service of Ahmad Dahlan University has facilitated, Yogyakarta 4 Muhammadiyah High School and Umbulharjo Yogyakarta Public Health Center.

\section{REFERENCES}

[1] N. Nisa, D. Dharminto, A. Farid, M. Atik . 2018. Development of Android-based Teenage Reproductive Health Education Application for Biology Learning in 2017 Pius Purworejo District, Journal of Public Health (e-Journal) Volume 6, Nomor 1, Januari 2018 (ISSN: 2356-3346).
[2] P. Ditha, 2017. The Portrait of Media Health Information For Urban Community in The Digital Era. IPTEK-KOM, Vol. 19 No. 2, Desember 2017: 149-162 ISSN 2527 4902.

[3] S. Eko Budi, K. M. Faizal. Mobile-Based Health Service Information Systems Integrating Institutions Of Health Services In Pekalongan City. The journal Research and Development city of Pekalongan vol. 11 of 2016.

[4] H. Basit, 2014. Relationship between the System Development Life Cycle and Software Quality Criterions for Achieving a Quality Software Product. International Journal of Computer Applications (0975 - 8887) Volume 104 - No 10, October 2014.

[5] Balaji, S., Murugaiyan, M., (2012). Waterfall vs. VModel vs. Agile: A comparative study on SDLC. International Journal of Information Technology and Business Management 2(1), 26-30.

[6] K. Anureet, K. Kulwant, 2015. Suitability of existing Software development Life Cycle (SDLC) in context of Mobile Application Development Life Cycle (MADLC). International Journal of Computer Applications (0975 8887) Volume 116 - No. 19, April 2015.

[7] Tejas Vithaniand Anand Kumar (2014), Modeling the Mobile Application Development Lifecycle, Proceedings of the International MultiConference of Engineers and Computer Scientists 2014 Vol I,IMECS 2014, March 12 - 14, Hong Kong.

[8] Liu, B., 2011, Web Data Mining, 2nd Edition, Springer, Berlin.

[9] Bird, S., Loper, E. dan Klein, E., 2009, Natural Language Processing with Python, O'Reilly Media, California. 